\title{
Research and Analysis of Weichat Public Platform \\ - Based on Sujiatun Hepan Community
}

\author{
LI Yali, ZHU Donglian
}

College of Finance and Economics, Jiangxi University of Technology ,Nanchang,China, 330098

Keywords: Weichat; Weichat public platform; Research and Analysis; Platform plan

Abstract. Weichat is a mobile communication software launched by Tencent in 2011. Weichat is more and more popular because of its simple usage, convenient chat communication, rich and colorful service function, unique users' experience and commercial potential with high stunt. Applying Weichat public platform to government affair management and community management service can both make full use of the advantages of Weichat which are high utilization rate and wide influence rage and complete government's work by the strong background support function of government e-government servics, which has the vital significance to better promote the government's work, provide the public with more quality and more thoughtful public service.

\section{Overview}

Weichat public platform is a new function module based on Weichat launched by Tencent. Through the platform, both individuals and enterprises can establish public platforms on which five categories of contents which are text, images, voice, video, and graphic news can be published. Currently, Weichat public platform supports PC web login and mobile Internet client login. Bind a private account and group messages can be launched. Weichat public platform mainly promotes cooperation business to celebrities, government, media and enterprises institutions. Here you can through channels to promote brands to the platform. Weichat public platform was officially launched on August 23rd, 2012, which was named "official platform" and "media platform", to create a better user experience and form a different ecological cycle.

\section{The survey of community Weichat platform}

Community Weichat platform is the Weichat service platform or subscription number which is the imitation of network community. It focuses on community daily management and provides various service for community residents. Community Weichat platform inherits the convenience and interacted of Weichat platform and also combines with accurate and democracy of community management. Weichat platform is more and more popular in community especially in young people because of its timeliness, convenience, interaction and the community service refinement trail behind it.

\section{The plan of the Weichat platform of Sujiatun Hepan community}

Function need analysis of community Weichat platform. The goal of Sujiatun Hepan community is to establish a comprehensive community. Weichat platform which takes community residents as center and combines with consulting, information release and convenient service and exchange interaction. To achieve this goal, each factor of the platform will be given full consideration. Firstly, the platform is to serve the community, thus the platform function should include all the information which is needed in community residents' daily life and work, which residents can look up at any time. Then, among the functions, some parts should be added which are closely linked with the residents' lives and interests to let residents often view this information, which will retain many users.

Interactive module planning. "Interaction" module should achieve the functions of 
information release, upload and display of information, mutual communication and so on. There are 6 sub modules of "Interaction" module:

"Interaction·Asking for help" for consulting, aspirations, leaving messages, filling out relevant information and waiting for a response.

"Interaction-Touching everybody" for uploading the photos residents take conveniently to record the touching moment and to show the spirit of community residents.

"Interaction-Making you laugh" for users to upload jokes, interesting news and other information.

"Interaction·Helping each other" for residents to seeking help when meeting with difficulties; for residents to provide help and service for the ones in need.

"Interaction, " for recommending the surrounding commercial service experience.

"Interaction, information first whiff" for listing the surrounding traffic, education, health, social security, civil affairs, housing, entertainment and sports, tourism, information service hot-line, etc.

Convenience module plan. Convenient module contain three parts. Two of them focus on the information query, in which one is the introduction of the community, the other is the community convenience of service. The other one is the functional module, focusing on for the convenience of business:

"Into the community" : the functions are 1. A brief introduction about the community, 2. The community LOGO and connotation, 3. The declaration of the community, 4. Community honor, 5. Community phone number.

"Community service" :

1) Insurance:

2) Retirement services

3) Unemployment loans

4) Family planning service

5) Service for disabled

6) Difficulties for help

7) Organization and management

8) Service for elderly

9) Community activities

10) Other service: one-time halal meat price subsidies for Hui people, etc.

"Convenience of business":

1) Household maintenance

2) Home appliance repair

3) Domestic service

4) Commodity distribution

5) Service around the community

6) Health care

7) Service and care for the aged

8) Daily help

9) Job hunting

10) Legal aid

11) Public service

12) Commonly used phone numbers

News module plan. News module is mainly to provide important domestic information and community information for community residents, which mainly focuses on information release:

1) Community dynamic

2) Local information

3) Domestic news 


\section{Platform operation}

The success of the community Weichat platform does not only depend on platform development and planning, the operation after launch plays a more critical role. From the former propaganda, the information collection and edition to handling different issues, good operation is needed. Otherwise, even through the advance publicity for the platform brings a large number of users, they will be less and less as time passes by, which eventually becomes a big failure of community management. And successful operation will bring good service experience to community residents .

Operating within the community platform. Platform propaganda:The first thing to do after the community platform is launched is to let people know that the community has the platform, let people fully realize the role of the platform, and then to attract people to the platform. Early propaganda can make people fully understand and know Weichat community platform and let people accept such a platform, which are the foundation for the future work about carrying Weichat platform. The Weichat public platform of Sujiatun Hepan community can be promoted through the following several aspects:

1) Posters.

2) Meetings.

3) Ideological work of elderly people in the community.

4) Messages and Emails.

Content services:

Community Weichat public platform does not focus on the form but the content. Good content can make people feel kind, make residents fully recognize platform and community management work, make residents realize the advantages of Weichat platform and make the community management work more convenience. Weichat platform of Sujiatun Hepan community platform content services can be started from the following several aspects:

1) Handling affairs

2) Community news promotion

3) Information feedback processing

Community surrounding operation. Since the beginning of Weichat, it is an open communication platform. It is destined that Weichat cannot be confined to a closed area, especially Weichat platform. Community Weichat platform cannot be limited within the community. the community life is a big circle, which is not just the community itself, but also includes the community surrounding environment, such as education, business, housekeeping, etc. Community Weichat platform should also be linked with the community surroundings, forming a large-scale comprehensive management platform based on Weichat platform and integrated with community residents, community itself and the surrounding. In order to achieve this goal, the community surrounding operation has become an important part. The surrounding operation of Weichat platform of Sujiatun Hepan Community can be carried out from the following aspects.

1) Housekeeping

2) Pets

3) Private tutors

4) Shopping malls

5) Second-hand markets

Convenience public service. Weichat public platform of Sujiatun Hepan Community will provide a variety of convenient public services, such as weather forecast, entertainment and sports information, traffic lines, gas and water query and payment, traffic violation query and express query, etc. In order to realize the service functions, Hepan Community Government needs to reach the cooperation with these departments, needs to connect the community Weichat platform with weather, traffic, logistics, municipal and other platforms. When residents query information, 
there is real-time information exchange between two platforms, which shows the query results to the Weichat platform to complete the query.

\section{Conclusion}

In the current social background, the Weichat platform of government affairs will be more popular in the future and become an integral part of the day-to-day management. As the functions of Weichat platform becoming more perfect, the application of Weichat platform also will be more and more wide and will gradually penetrate into every aspect of our lives. In community management, community Weichat platform has huge advantages and it will get great progress in the future. Now, the function of the community Weichat platform is given priority to information query and release. These simple functions have provided great convenience to community residents, in the future, with more perfect function of the functions of Weichat platform and the increasing open development interface, the functions of the community Weichat platform may be more diversity. In the future, the community Weichat platform is not just an information publishing platform, at the same time it will be a business platform and e-government platform. In the platform, many commercial contents will be added, such as "supermarket" and "express", "market", etc., through which community residents have no needs to leave home for buying their needs of daily necessities, fruits and vegetables and meat, etc.. The things residents buy can be delivered by the special delivery staff. When the seamless connection between government affairs Weichat platform and the government is achieved, residents will be able to handle the issues such as insurance, life after retirement, marriage, fertility, etc., which truly achieves the goal of "service through Weichat".

\section{Reference}

[1] Zhao Jing, Li Bei. Current situation of the development of Weichat public platform[J]. News Practice, 2013 ( 8).

[2] Cai Wen, Weng Zhihao. Weichat public platform: another opportunity of news dissemination change--- taking the Weichat public platform of "CCTV NEWS" as an example[J]. Shanghai Journalism Review, 2013 (7) .

[3] Qi Yanan. New media changes induced by Weichat[J]. China Broadcast, 2013(5).

[4] Wang Xian. The application of of Weichat in broadcast[J], Science \& Technology for China's Mass Media, 2013[6]2.

[5] Lu Bo, Public service platform bringing new changes[J]. China Telecom industry, 2013 (10).

[6] Gao Yunying, Research of the application of Weichat public service oriented e-government system[D], Journal of Fujian Party School, 2013(10).

[7] Tianjin information center.Government affairs Weichat: network communicate administration new platform[J], 2013(5).

[8] Chen Chaoxian. The status, problems and countermeasures of the development of e-government Weichat[D]. Journal of Qingdao school of administration of Qingdao Party School, 2013(4).

[9] Deng Yinghua, Wang Bosi. Can government affairs Weichat promote "authority"?[J]. China Newspaper Industry, 2013(6)1.

[10] Zou Wei, Yi Qiu. Government Weichat making the government more effective[J]. Shanghai Informatization, 2013(7). 